\title{
The role of the pediatrician in youth violence prevention
}

\author{
Soon Ki Kim, MD, PhD', Nam Su Kim, MD, PhD² \\ ${ }^{1}$ Department of Pediatrics, Inha University Hospital, Inha University School of Medicine, Incheon \\ ${ }^{2}$ Department of Pediatrics, Hanyang University Seoul Hospital, Hanyang University College of Medicine, Seoul, Korea
}

School bullying has become a major social problem in Korea after the emergence of media reports on children who committed suicide after being victimized by bullies. In this article, we review the characteristics of bullying, and investigate the role of the pediatrician in the prevention of and intervention against bullying and school violence. Bullying can take on many forms such as physical threat, verbal humiliation, malicious rumors, and social ostracism. The prevalence of bullying in various countries is approximately $10 \%$ to $20 \%$. In Korea, the prevalence of school violence is similar but seems to be more intense because of the highly competitive environment. From our review of literature, we found that children who were bullied had a significantly higher risk of developing psychosomatic and psychosocial problems such as headache, abdominal pain, anxiety, and depression than those who were not bullied. Hence, it is important for health practitioners to detect these signs in a child who was bullied by questioning and examining the child, and to determine whether bullying plays a contributing role when a child exhibits such signs. Pediatricians can play an important role in the prevention of or intervention against school violence along with school authorities, parents, and community leaders. Moreover, guidelines to prevent school violence, such as the Olweus Bullying Prevention Program, KiVa of the Finish Ministry of Education, and Connected Kids: Safe, Strong, Secure of the American Academy Pediatrics, should be implemented.

Key words: Bullying, Violence, Pediatrician, Child, Adolescent, Korea

\section{Introduction}

School bullying has emerged as a major social problem in Korea after a 14-year-old middle school student in Daegu committed suicide after having been harassed for months by some classmates. Bullying and school violence are not recent issues but have become a growing concern owing to media reports on children who were severely injured or who committed suicide after being victimized by bullies. In fact, reports of school violence in the wake of a recent series of suicide cases among children have been a cause for alarm among Koreans.

Children and adolescents face serious short- and long-term physical and psychological consequences as victims, witnesses, and perpetrators of violence ${ }^{1)}$. Recently, researches have shown that children who are bullied manifest adjustment problems ${ }^{2-6}$. Bullying affects many children and lays the groundwork for long-term depression, suicidality, psychotic symptoms, conduct problems, and psychosomatic concerns among children and teens.

In this article, we review the characteristics of bullying, children who were bullied,
Corresponding author: Soon Ki Kim, MD

Department of Pediatrics, Inha University Hospital, Inha University School of Medicine, 27 Inhang-ro, Jung-gu, Incheon 400-711, Korea

Tel: +82-32-890-2843

Fax: +82-32-890-2844

E-mail: pedkim@inha.ac.kr

Received: 20 August 2012

Accepted: 28 November 2012
Copyright $(2013$ by The Korean Pediatric Society

This is an open-access article distributed under the terms of the Creative Commons Attribution NonCommercial License (http://creativecommons.org/ licenses/by-nc/3.0// which permits unrestricted noncommercial use, distribution, and reproduction in any medium, provided the original work is properly cited. 
bullies, and the physical and psychological consequences in children who were bullied. Moreover, we investigate the role of the pediatrician in the prevention of and intervention against bullying and school violence in young and adolescent students.

\section{Definition}

Bullying is an act of repeated aggressive behavior performed to intentionally hurt another person, physically or mentally. We further define "bullying" according to the definition by Olweus ${ }^{7)}$, creator of the Olweus Bullying Prevention Program as follows:

A person is bullied when exposed, repeatedly and over time, to the negative actions of one or more other persons and has difficulty defending oneself. Olweus defines "negative action" as "when a person intentionally inflicts injury or discomfort upon another person, through physical contact, through words, or in other ways." The definition of "bullying" includes the following 3 important components: 1) aggressive behavior that involves unwanted, negative actions; 2) a pattern of behavior repeated over time; and 3) an imbalance of power or strength. In this article, we define "school violence" as an incident from bullying-related behaviors. Contrary to bullying, teasing usually involves 2 or more friends who act together in a way that seems fun to all the people involved. Often, they tease each other equally but never engage in physical or emotional abuse. It is not bullying when 2 students of about equal strength or power argue or fight.

\section{Types of bullying}

Bullying can take on many forms, including physical threat, verbal humiliation, malicious rumors, and social ostracism ${ }^{8)}$. As part of the Olweus Bullying Questionnaire ${ }^{9)}$, students are asked if they have been bullied in any of the following 9 ways:

1) Verbal bullying including derogatory comments and bad names.

2) Bullying through social exclusion or isolation.

3) Physical bullying such as hitting, kicking, shoving, and spitting.

4) Bullying through lies and false rumors.

5) Having money (money extortion) or other things taken or damaged by students who bully.

6) Being threatened or being forced to do things by students who bully, as in slave contracts.

7) Racial bullying.

8) Sexual bullying.

9) Cyber bullying (via celluar phone or the Internet).
Bullying can occur in nearly any part in or around the school building, although it may occur more frequently in classrooms and on the playgrounds. A survey conducted in 2012 revealed that school toilets are also a frequent location of school violence ${ }^{10)}$.

\section{Prevalence}

The prevalence of bullying in various countries is approximately $10 \%$ to $20 \%{ }^{11}$. In a survey study, Olweus ${ }^{7)}$ reported that $15 \%$ of students in elementary and secondary/junior high schools (ages 7 to 16 years) in Norway were involved in bullying either as victims or as bullies. A recent study in the United States on student involvement in bullying indicated that $17 \%$ of students self-reported having been bullied "sometimes" or "more often" ${ }^{12)}$. In a cross-national study of students between the ages of 11 and 15 years from 25 countries, student involvement in bullying varied from $9 \%$ to $54 \%{ }^{13)}$.

According to the Foundation for Preventing Youth Violence in Korea ${ }^{14)}$, the self-reported prevalence of school violence was $17.3 \%$ in $2006,16.2 \%$ in $2007,9.4 \%$ in $2009,11.8 \%$ in 2010 , and 18.3\% in 2011 (Fig. 1). The prevalence of bullying was $12.6 \%$ in $2006,15.1 \%$ in $2007,12.4 \%$ in 2009 , and $15.7 \%$ in 2011. The prevalence of students who were aware of school violence was 28.6\% in 2008, 32.8\% in 2009, 38.1\% in 2010, and $41.7 \%$ in 2011, indicating the severity of school violence. However, approximately $70 \%$ of the offenders did not think that their actions were wrong, with one-third saying they did it for fun.

With the school system being highly competitive, Korean students are under a lot of pressure and have to spend more time at school, making them more prone to various forms of bullying and school violence. Recently, the number of students who possess cellular phones has increased, making cellular

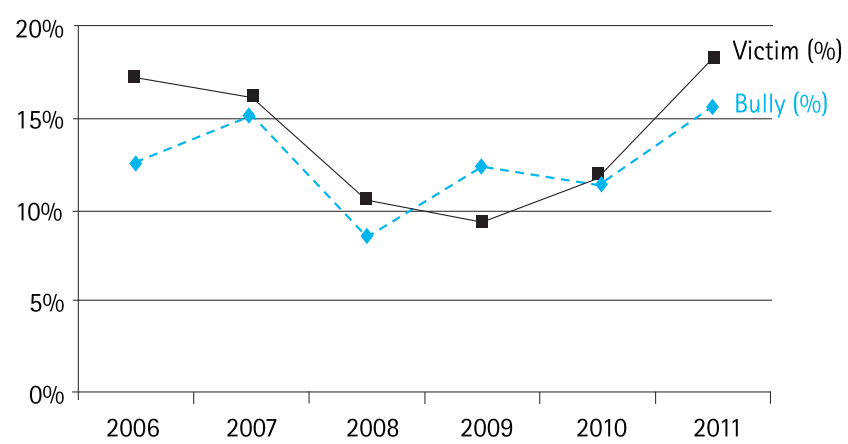

Fig. 1. Annual prevalence rates of bullying among Korean students from the fourth grade of elementary school to the second grade of high school, between 2006 and 2011 (adapted with permission from Foundation for Preventing Youth Violence $\left.{ }^{14}\right)$. 
phones effective weapons for cyber bullying.

A recent large-scale nationwide survey ${ }^{10)}$ conducted by the Ministry of Education, Science and Technology revealed that $12.3 \%$ of the respondents self-reported being bullied during the last 12 months, of whom 15.2\% were elementary school students; 13.4\%, middle school students; and 5.7\%, high school students, suggesting that middle school students are more than twice as likely than high school students to be affected by school violence.

There are at least 2 reasons for the high rate of violence in middle school ${ }^{12)}$. First, early adolescence is a difficult stage within the framework of puberty, and most young teenagers are physically hyperactive but have not yet learned acceptable social behavior. Second, it is most often during middle school that many students come in contact for the first time with young people from different backgrounds and distant neighborhoods, and they easily get tempted to join school gangs.

Students from multicultural families are often bullied and subjected to school violence ${ }^{15)}$. In Korea, approximately 300,000 children having biracial family backgrounds attend schools from the elementary to high level. Their skin color and language may be the target of bullying or school violence by their classmates.

On the other hand, students with disabilities are more likely to be bullied ${ }^{16)}$. Bullying is not limited to students who are visibly disabled, such as those with physical deformities such as a cleft lip, but also involves those with learning disabilities such as attention-deficit hyperactivity disorder, autism, and dyspraxia.

\section{Characteristics of students who are bullied}

Students who are being bullied often exhibit some warning signs. According to Olweus ${ }^{9}$, these students may

- have torn, damaged, or missing pieces of clothing, books, or other belongings

have unexplained cuts, bruises, and scratches from fighting

have few, if any, friends with whom they spend time

seem afraid of going to school, walking to and from school, riding the school bus, or taking part in organized activities with peers, such as those of clubs or sports

take a long, "illogical" route when walking to or from school

- lose interest in doing schoolwork or suddenly begin to do poorly in school

appear sad, moody, teary-eyed, or depressed when coming home from school

complain frequently of headaches, stomachaches, or other physical problems

- frequently have bad dreams or trouble sleeping
- experience loss of appetite

- appear anxious and have low self-esteem

Children typically targeted by bullies are often smaller or younger than the bullies are. Being more sensitive and cautious than other children, they usually blame themselves for the attack, consequently feeling worthless, anxious, depressed, and insecure. Those who are bullied at an early age are also often bullied later in life. Being a target of bullying affects the development of a child's social skills, and hampers the child's future success at school and academics.

While physical threats may seem more terrifying than verbal threats, children who are bullied are just as devastated by ostracism or other forms of social trauma. These children experience real hostility that interferes with their social and academic development.

Perren and Alsaker ${ }^{17)}$ examined social behaviors and peer relationships among children between the ages of 5 and 7 years who were involved in bullying in kindergarten. They discovered that children who were bullied were more submissive, more withdrawn, more isolated, less cooperative, less sociable, had fewer leadership skills, and frequently had no playmates than those children who were not bullied. Secondary school students (aged 13 years) who were bullied had high risks of depression and anxiety over the following school year ${ }^{18}$.

Fekkes et al. ${ }^{19)}$ and Gini and Pozzoli ${ }^{20)}$ found that school children who were bullied had higher risks for psychosomatic symptoms and depression than those who were not bullied. Given that psychosomatic and psychosocial health problems follow an episode of bullying, they recommended that medical practitioners screen patients with these problems for signs of being bullied. In addition, because children with depressive symptoms and anxiety are at an increased risk of being bullied, parents of these children should be guided in terms of tapping the appropriate resources to enhance their children's coping skills.

Bullying can result in loneliness, depression, anxiety ${ }^{21,22)}$, low self-esteem, increased susceptibility to illness ${ }^{23}$, poor grades, and suicidal thoughts. The aggressive behavior of a bully interferes with a child's ability to think clearly and rationally. In bullying, the bully and the child being bullied become less sensitive to violence. In many cases, the friends and classmates of the bully and the one being bullied accept the violence as normal.

The effects of bullying can be serious and even fatal. Suicidal ideation was especially frequent among bullied children who had little social support ${ }^{24)}$. Some children who experienced bullying committed suicide rather than continue to endure being bullied $^{25)}$.

In the long-term, bullying can lead to posttraumatic stress disorder and inability to form social relationships. Those who 
have been targets of bullying may experience long-term emotional and behavioral problems. Children who are bullied manifest adjustment problems, including internalizing disorders, externalizing disorders, social difficulties, physical health problems, and suicidal ideation ${ }^{2,5}$. Chronic victimization increases the risk for low self-esteem, the use of psychotropic medications, and the tendency for violent actions toward self and others ${ }^{8)}$. Identifying incidents of bullying and victimization during early school years, particularly among boys, may be useful in identifying those who are at risk for psychiatric disorders in early adulthood ${ }^{6}$.

\section{Characteristics of students who bully others}

Determining the characteristics of students who bully others may help prevent bullying and allow for early intervention. Often, bullies seem to be preferred by other aggressive playmates, especially among boys. This affiliation among aggressive children might lead to an increase in bullying activities. Caregivers of children should be alert to the following patterns of aggression, as described by Olweus ${ }^{9}$ :

a positive attitude toward violence and the use of violent means.

- a strong need to dominate and subdue other students and get their own way.

being impulsive, aggressive, or easily angered.

lack of empathy toward students who are bullied.

- defiance and aggression toward adults, including teachers and parents.

- involvement in antisocial or rule-breaking activities such as vandalism, delinquency, and substance abuse.

- having greater physical strength than others in general and the students they bully in particular (especially in boys).

being more likely to report owning a gun for risky reasons such as to gain respect or frighten others.

Bullies are often aggressive toward teachers, parents, siblings, and peers and have a strong desire for power and domination. They seem to enjoy being "in control" and subduing others ${ }^{11)}$. Those who bully their peers are also more likely to get into frequent fights, steal and vandalize property, drink alcohol, smoke, have poor grades, perceive a negative climate at school, and carry a weapon than those who do not ${ }^{9)}$. However, not all students who bully others have obvious behavioral problems or are engaged in rule-breaking activities. Some of them are highly skilled socially and good at ingratiating themselves with their teachers and other adults. A student who bullies can have a wide-ranging impact on the students they bully, the students who observe bullying, and the overall climate of the school and community. This is true of some boys who bully, but is perhaps even more common among girls who bully. For this reason, it is often difficult for adults to discover or even suspect that these students engage in bullying behavior.

When episodes of bullying are rewarded or ignored, children do not progress to more mature means of influencing others. Being described as a bully over time is associated with an increased incidence of criminal activity in adulthood. Bullies are less social, but they have better leadership skills than children who do not bully. Bullies belong to larger social clusters and frequently associate with other bullies or bully victims.

\section{Observers of bullying}

Students who witness acts of bullying may feel that they are in an unsafe environment. The various reasons why children choose not to intervene include being worried that intervening will make the situation worse or the risk of becoming the next to be bullied. The fear that children experience as bystanders is a direct cause of the decline of antibullying attitudes.

The effects of observing bullying may include feeling fearful, powerless to act, guilty for not acting, and tempted to participate. When bullying continues and school authorities do not take action, the entire school climate can be affected in the following ways ${ }^{9)}$ :

- The school develops an environment of fear and disrespect.

- Students have difficulty learning.

- Students feel insecure.

- Students dislike the school.

- Students perceive teachers and staff to have little control and not care about them.

\section{Prevention and intervention}

The goal of prevention and intervention strategies is to ultimately stop school violence. The Korean government has established several programs against bullying since the 1990s; however, they were not effective. Antisocial systems such as 'Iljin' should be subjected to disciplinary action. The school culture where students desire to get involved in a "first-class faction" should be changed to promote a more harmonious and less competitive school climate. The Olweus Bullying Prevention Program ${ }^{9}$ is a successful system-wide program at the following 4 levels: school, classroom, individual, and community, which includes intervention and education for those who are bullied and those who bully. The Finnish Ministry of Education developed a new national antibullying program, KiVa ("against bullying") ${ }^{26)}$.

KiVa involves actions to prevent bullying and tackle cases 
of bullying that are revealed. The actions are targeted to all students in a school and include efforts made to build childrens' capacity to behave in constructive ways, take responsibility of discouraging bullying, and support those who are bullied. KiVa has been shown to be effective in reducing the incidence of bullying. According to the United States Centers for Disease Control, the following 4 levels are targeted by violence prevention programs: the society in general, the school community, the family, and the individual ${ }^{27)}$.

Among those including above mentioned systems, we Koreans had better establish a better standard of success in developing appropriate antibullying and school violence prevention programs. Guidelines of clinical practice for the intervention, management, and prevention of youth violence should include ${ }^{28)}$ primary care and violence prevention protocols; use of a comprehensive approach, screening, and counseling for children and their families during the course of a routine health checkup; appropriate and timely treatment and referral for the violencerelated problems identified; and maintenance of an accurate database of community-based counseling and treatment resources. Whenever applicable, this database should be available through the practice's electronic health record system or linked to the practice's internal and external websites. As Korea is an Internet-strong nation, we believe that it is capable of organizing and managing an Internet-based school violence prevention program such as the Olweus Bullying Prevention Program, and equipping its educational system with a program such as the Finnish KiVa program ${ }^{26,29)}$. Children with anxiety or depression and additional possible risk factors for victimization, such as having few friends, being unpopular, or being subassertive, should be referred to the school personnel in charge or should be trained in social skills to prevent them from being victimized by bullies.

\section{Role of pediatricians}

Children who were bullied had significantly higher risks of developing psychosomatic and psychosocial problems (headache, abdominal pain, anxiety, depression, and secondary enuresis) than children who were not bullied ${ }^{30}$. Therefore, it is important for health practitioners to detect these findings by thoughtfully questioning and examining the child, and investigating whether bullying plays a contributing role when a child exhibits such symptoms. It is best for well-qualified pediatricians to perform the evaluation because of their strong experience in medical practices and routine counseling in an outpatient clinic setting. Because clinical physicians usually do not have much time to provide counseling on the prevention of youth violence, the use of a questionnaire as a screening method or recording of a patient's history may be practical and effective. The developmental status of children and adolescents can vary depending on the individual; therefore, it is essential to understand the state of their physical and mental development at an individual level. Pediatricians seem to be the most qualified individuals to perform the assessment because of their long history of addressing the major health issues of children in Korea by promoting access to health care, providing preventive care such as immunizations, and fostering early care and education.

Moreover, pediatricians in Korea have been promoting good adolescent culture by making certain changes, such as renaming the Department of Pediatrics to the Department of Children and Adolescents for building the image of hospitals as adolescentfriendly. Therefore, pediatricians can play an important role for the prevention of or intervention against school violence, along with school authorities, parents, and community leaders. There is evidence to suggest that pediatricians have leadership roles in violence prevention education and advocacy in communitybased settings ${ }^{28)}$. Primary care pediatricians have access to atrisk children and teens involved in violence-related behaviors and are in the position to advice parents and caregivers ${ }^{31)}$.

However, all physicians in Korea are under the Korean Health Insurance System and can therefore spare only a short time to give counseling on the prevention of youth violence. Nevertheless, they could magnify their influence by fortifying their access to community resources via an organized system. The physician can incorporate counseling regarding bullying and school violence into the routine child examinations or clinical practices. In a study on youth violence prevention, it was found that parents perceived the physician as an educator who could directly influence their child to make positive choices that would lead to less violence ${ }^{32)}$. If physicians teach children some basic skills to stay safe, violence could be prevented. Furthermore, if a physician recognizes that a patient is exposed to violence in the community or family, a referral to an appropriate community program could be made, given that clinicians are made aware of the various community resources. In addition, communicating via the telephone may reduce the barriers to participation in parent training ${ }^{33)}$.

Korea needs to develop guidelines such as the primary care violence prevention protocol Connected Kids: Safe, Strong, Secure $^{34)}$, which was established by the American Academy in 2005 to address violence prevention in the context of routine child health care. As a primary step, we suggest the following criteria, which are adapted from the Connected Kids protocol:

- A working familiarity with the main protocol

- Use of a comprehensive approach for anticipatory guidance, screening, and counseling of children and families during the course of routine health maintenance 
Appropriate and timely treatment and referral for violencerelated problems identified

Maintenance of a database of community-based counseling and treatment resources

Adequate publicly supported, community-based, behavioral health services

Bullying awareness by teachers, educational administrators, parents, and children, coupled with adoption of evidencebased prevention programs

The role of health professionals as appropriate public health messengers through print, electronic, or online media, and incorporation of content related to youth violence prevention in electronic health records, including screening prompts and links to parent educational materials

- Formal continuing medical education or professional development programs

- Learning about community resources for children and adolescents

- Contributing data to existing intentional injury surveillance systems

We recommend that children and adolescents receive some form of education designed to help prevent bullying and criminal activities in schools, such as that in the Finnish KiVa program ${ }^{26}$. More consultants who are professional need to be identified and deployed to schools nationwide so that students can more easily access necessary counseling. School personnel in charge, community and local pediatricians, and parents must work together and build closer relationships to effectively prevent school violence. The definition of the role of clinicians in youth violence prevention and management should be endorsed by the Korean Medical Association, the Korean Pediatric Society, the Korean Academy of Family Medicine, and Child Psychiatrist. In Korea, most children with psychosocial problems are treated in the general medical setting rather than in the mental health setting. Therefore, pediatricians should advocate that parents and school personnel actively participate in implementing changes to stop bullying and openly support legal actions.

\section{Acknowledgment}

This work was supported by Inha University Research Grant.

\section{References}

1. The role of the pediatrician in youth violence prevention in clinical practice and at the community level. American Academy of Pediatrics Task Force on Violence. Pediatrics 1999;103:173-81. 2. Arseneault L, Walsh E, Trzesniewski K, Newcombe R, Caspi
A, Moffitt TE. Bullying victimization uniquely contributes to adjustment problems in young children: a nationally representative cohort study. Pediatrics 2006;118:130-8.

3. Hawker DS, Boulton MJ. Twenty years' research on peer victimization and psychosocial maladjustment: a meta-analytic review of cross-sectional studies. J Child Psychol Psychiatry 2000;41: 441-55.

4. Nansel TR, Overpeck MD, Haynie DL, Ruan WJ, Scheidt PC. Relationships between bullying and violence among US youth. Arch Pediatr Adolesc Med 2003;157:348-53.

5. Kim YS, Koh YJ, Leventhal B. School bullying and suicidal risk in Korean middle school students. Pediatrics 2005;115:357-63.

6. Sourander A, Jensen P, Ronning JA, Niemela S, Helenius H, Sillanmaki L, et al. What is the early adulthood outcome of boys who bully or are bullied in childhood? The Finnish "From a Boy to a Man" study. Pediatrics 2007;120:397-404.

7. Olweus D. Bullying at school: basic facts and effects of a school based intervention program. J Child Psychol Psychiatry 1994;35:1171-90.

8. Glew GM, Frey KS, Walker WO. Bullying update: are we making any progress? Pediatr Rev 2010;31:e68-74.

9. Olweus Bullying Prevention Program [Internet]. Center city: Hazelden Foundation; c2012 [cited 2012 Aug 15]. Available from: http://www.violencepreventionworks.org/public/index.page.

10. Ministry of Education, Science and Technology. Survey of school violence and successive manual coping with school violence [Internet]. Seoul: Ministry of Education, Science and Technology; c1998-2008 [cited 2012 Aug 15]. Available from: http://www. mest.go.kr/web/60879/ko/board/view.do?bbsId=291GtboardSeq= 28751 $\mathrm{Ctmode}=$ view.

11. Glew G, Rivara F, Feudtner C. Bullying: children hurting children. Pediatr Rev 2000;21:183-9.

12. Nansel TR, Overpeck M, Pilla RS, Ruan WJ, Simons-Morton B, Scheidt P. Bullying behaviors among US youth: prevalence and association with psychosocial adjustment. JAMA 2001;285:2094100.

13. Nansel TR, Craig W, Overpeck MD, Saluja G, Ruan WJ; Health Behaviour in School-aged Children Bullying Analyses Working Group. Cross-national consistency in the relationship between bullying behaviors and psychosocial adjustment. Arch Pediatr Adolesc Med 2004;158:730-6.

14. Foundation for Preventing Youth Violence. Survey of school violence 2011 [Internet]. Seoul: Foundation for Preventing Youth Violence; [copyright year unknown] [cited 2012 Aug 15]. Available from: http://edujikim.com/.

15. von Grunigen R, Perren S, Nagele C, Alsaker FD. Immigrant children's peer acceptance and victimization in kindergarten: the role of local language competence. Br J Dev Psychol 2010;28(Pt 3):679-97.

16. Sentenac M, Gavin A, Arnaud C, Molcho M, Godeau E, Nic Gabhainn S. Victims of bullying among students with a disability or chronic illness and their peers: a cross-national study between Ireland and France. J Adolesc Health 2011;48:461-6.

17. Perren S, Alsaker FD. Social behavior and peer relationships of victims, bully-victims, and bullies in kindergarten. J Child Psychol Psychiatry 2006;47:45-57.

18. Bond L, Carlin JB, Thomas L, Rubin K, Patton G. Does bullying cause emotional problems? A prospective study of young teenagers. BMJ 2001;323:480-4.

19. Fekkes M, Pijpers FI, Verloove-Vanhorick SP. Bullying behavior and associations with psychosomatic complaints and depression in victims. J Pediatr 2004;144:17-22.

20. Gini G, Pozzoli T. Association between bullying and psychoso- 
matic problems: a meta-analysis. Pediatrics 2009;123:1059-65.

21. Kochenderfer BJ, Ladd GW. Peer victimization: cause or consequence of school maladjustment? Child Dev 1996;67:1305-17.

22. Ladd GW, Kochenderfer-Ladd B. Identifying victims of peer aggression from early to middle childhood: analysis of crossinformant data for concordance, estimation of relational adjustment, prevalence of victimization, and characteristics of identified victims. Psychol Assess 2002; 14:74-96.

23. Williams K, Chambers M, Logan S, Robinson D. Association of common health symptoms with bullying in primary school children. BMJ 1996;313:17-9.

24. Rigby K. Peer victimisation at school and the health of secondary school students. Br J Educ Psychol 1999;69(Pt 1):95-104.

25. Kim YS, Leventhal B. Bullying and suicide: a review. Int J Adolesc Med Health 2008;20:133-54.

26. KiVa Koulu. There is no bullying in KiVa school [Internet]. Turku: University of Turku; [copyright year unknown] [cited 2012 Aug 15]. Available from: http://www.kivakoulu.fi/there-is-nobullying-in-kiva-school.

27. Hahn R, Fuqua-Whitley D, Wethington H, Lowy J, Liberman A, Crosby A, et al. The effectiveness of universal school-based programs for the prevention of violent and aggressive behavior: a report on recommendations of the Task Force on Community Preventive Services. MMWR Recomm Rep 2007;56(RR-7):1-12.
28. Committee on Injury, Violence, and Poison Prevention. Policy statement: Role of the pediatrician in youth violence prevention. Pediatrics 2009; 124:393-402.

29. Karna A, Voeten M, Little TD, Poskiparta E, Kaljonen A, Salmivalli C. A large-scale evaluation of the KiVa antibullying program: grades 4-6. Child Dev 2011;82:311-30.

30. Fekkes M, Pijpers FI, Fredriks AM, Vogels T, Verloove-Vanhorick SP. Do bullied children get ill, or do ill children get bullied? A prospective cohort study on the relationship between bullying and health-related symptoms. Pediatrics 2006;117:1568-74.

31. Cheng TL, Schwarz D, Brenner RA, Wright JL, Fields CB, O'Donnell R, et al. Adolescent assault injury: risk and protective factors and locations of contact for intervention. Pediatrics 2003; 112:931-8.

32. Barkin S, Ryan G, Gelberg L. What pediatricians can do to further youth violence prevention: a qualitative study. Inj Prev 1999;5:53-8.

33. Borowsky IW, Mozayeny S, Stuenkel K, Ireland M. Effects of a primary care-based intervention on violent behavior and injury in children. Pediatrics 2004;114:e392-9.

34. Sege RD, Flanigan E, Levin-Goodman R, Licenziato VG, De Vos E, Spivak H, et al. American Academy of Pediatrics' Connected Kids program: case study. Am J Prev Med 2005;29(5 Suppl 2):215-9. 